Mongolian Academy of Sciences
Mongolian Journal of Chemistry
Institute of Chemistry \& Chemical Technology

\title{
Investigation on characterization of Ereen coal deposit
}

\author{
S.Jargalmaa ${ }^{1}$, B.Purevsuren ${ }^{1 *}$, Ya.Davaajav¹, B.Avid ${ }^{1}$, B.Bat-Ulzii', B.Ochirhuyag ${ }^{2}$ \\ ${ }^{1}$ Institute of Chemistry and Chemical Technology, MAS, Peace avenue, Ulaanbaatar 13330, Mongolia \\ ${ }^{2}$ School of Arts and Sciences, NUM, University Street 1, Ulaanbaatar 14201, Mongolia
}

ARTICLE INFO: Received 29 October 2015; revised 24 November 2015; accepted 30 November 2015

\begin{abstract}
The Ereen coal deposit is located $360 \mathrm{~km}$ west from Ulaanbaatar and $95 \mathrm{~km}$ from Bulgan town. The coal reserve of this deposit is approximately 345.2 million tons. The Ereen coal is used directly for the Erdenet power plant for producing of electricity and heat. The utilization of this coal for gas and liquid product using gasification and pyrolysis is now being considered. The proximate and ultimate analysis show that the Ereen coal is low rank D mark hard coal, which corresponds to subbituminous coal. The SEM images of initial coal sample have compact solid pieces. The SEM image of carbonized and activated carbon samples are hard material with high developed macro porosity structure. The SEM images of hard residue after thermal dissolution in autoclave characterizes hard pieces with micro porous structure in comparison with activated carbon sample. The results of the thermal dissolution of Ereen coal in tetralin with constant weight ratio between coal and tetralin (1:1.8) at the $450^{\circ} \mathrm{C}$ show that $38 \%$ of liquid product can be obtained by thermal decomposition of the COM (coal organic matter).
\end{abstract}

Keywords: pyrolisis, mineral compounds, petrographic analysis, thermal dissolution, SEM

\section{INTRODUCTION}

Coal is the most important organic resource of Mongolia. Mongolia has 20 billion tons of proven coal reserves and estimated resources totaling 173 billion tons, mostly of them is low-rank brown coal, but remains undeveloped due to a lack of infrastructure [1]. In Mongolia, coal is main energy carrier for thermal power plants and local boiler houses and there is almost no other form of largescale coal industry [2]. Apart from coal as primary energy fuel, different products such as metallurgical coke, coal tar, synthetic gases can be derived and manufactured from coal, which represents an important feedstock for chemical industry. Compared to oil and natural gas, the coal is more evently distributed in worldwide and often readily accessible e.g. by open-cast mining. Because of instability of the world oil market, the diversification of energ carriers is practically implemented in many countries with involvement of various non traditional types of organic raw materials, primarily, coal, whose reserves are much greater than oil and gas reserves. Coal samples from the Tavantolgoi deposit have been assessed for beneficiation [3] and coke production [4], samples from Baganuur, Bayanteeg and Shiveeovoo deposits for pyrolysis [5], hydrogenation [6] and gasification [7, 8]. Also samples from Ovdogkhudag and Aduunchuluun deposits have been assessed for their liquefaction potential using facilities in Japan [9]. However, coal of Ereen deposit has not been investigated in detail. The conversion of coal into oil and gas is a major issue in the country, which will affect the national safety and economic sustainable development. Therefore more detailed investigation of the above mentioned coal deposits by using odern instrumental analysis such as petrographic and different pyrolytic

*corresponding author: e-mail: bpurevsuren.icct@gmail.com

DOI: http://dx.doi.org/10.5564/mjc.v16i0.664 experimental methods is very important for the future development of coal processing industries in Mongolia. For this reason the coal of Ereen deposit has been investigated for the first time in detailed using thermal processing including pyrolysis and thermal dissolution and its characterization of the solid (hard residue) and liquid products.

\section{EXPERIMENTAL}

Sample preparation, proximate and ultimate analysis of coal from the Ereen deposit were performed according to Mongolian National Standards MNS 656-79, MNS 652-79, MNS 654-79, MNS 669-87 and MNS 89579. Petrographic analysis was conducted on polished particulate mounts following recommendations by the International Committee for Coal and Organic Petrology (ICCP) [10]. Vitrinite reflectance was measured using an Axio Imager M2m microscope and Fossil software on 50 individual vitrinite macerals in random mode. Resedimented vitrinite particles are characterized by higher reflectivity than autochthonous vitrinite. Usually, only the vitrinites with the lowest reflectance values are measured and reported. Maceral group analysis was performed using the same microscope and software by point counting of 500 individual macerals. The pyrolysis experiments of coal samples were performed in a laboratory vertical cylindrical retort made by stainless steel which could contain up to $1000 \mathrm{~g}$ of sample. The retort was placed in an electric furnace with a maximum temperature of $950^{\circ} \mathrm{C}$. A chrome-alumel thermocouple was immersed in the coal bed to measure the actual heating temperature. The retort was connected with an air-cooled iron tube and water-cooled laboratory glass condenser and a collection vessel for the condensate of liquid product. The non-condensable gases after water-cooled condenser were left the system through 
a thin glass tube. The experiments were carried out to final temperature of $900^{\circ} \mathrm{C}$ and the heating rate was $20^{\circ} \mathrm{C} \mathrm{min}{ }^{-1}$. The yields of products including solid residue (char), tar and pyrolysis water were determined by weigh and the yield of gases by differences. The thermal dissolution of coal samples was carried out in a stainless steel autoclave using tetralin as a hydrogen donor solvent. Prior to the treatment coal samples were air dried for $24 \mathrm{~h}$, powdered to a particle size $<0.2 \mathrm{~mm}$. Then $1 \mathrm{~g}$ of coal sample was mixed with $1.8 \mathrm{~g}$ tetralin (mass ratio 1:1.8), sealed in the autoclave and heated in a laboratory furnace for $2 \mathrm{~h}$ to temperatures of $350^{\circ} \mathrm{C}$, $400^{\circ} \mathrm{C}$ and $450^{\circ} \mathrm{C}$. After completion of each experiment, the autoclave was cooled to room temperature and all uncondensed gas and produced liquid products were removed, filtered and the solid residue (char) from the filter was subjected to sequential extraction with chloroform in a soxhlet apparatus. An extract of liquid products of thermal dissolution of coal in tetralin was distilled by a laboratory rotary evaporation apparatus for complete removing of chloroform. The degree of coal conversion was determined from the loss of the coal organic matter (COM) after extraction and also change in the ash contents of the initial coal samples and the insoluble residue. The yields of pyrolysis products including coal char, tar and pyrolysis water were determined by weighing and the yield of gases calculated by differences. The pyrolized coal samples $(10-15 \mathrm{~g})$ are placed in quarts tube and flowed by nitrogen to remove the oxygen and heated until $800^{\circ} \mathrm{C}$ and activated with high temperature steam for 120 minutes. The iodine number, $\%$ is defined as the number of milligrams of iodine adsorbed from an agueous solution by $1 \mathrm{~g}$ of activated carbon when the iodine concentration of the residual filtrate is $0.02 \mathrm{~N}$. Granular activated carbon is pulverized $(<0.1 \mathrm{~mm})$ and then dried at $150^{\circ} \mathrm{C}$ to constant weight. Depending on the activity of the carbon, weigh $1 \mathrm{~g}$ of the dried carbon, and transfer the weighed sample to a dry, glass stoppered $250 \mathrm{ml}$ flask then add by pipette $50 \mathrm{ml}$ of $0.1 \mathrm{~N}$ iodine solution. Stopper the flask immediately and shake it vigourously for 30 seconds. Filter by gravity through a filter paper immediately after the 30 seconds shaking period. Stir the filtrate in the breaker with a glass rod and pipette $50 \mathrm{ml}$ into a $250 \mathrm{ml}$ flask. Titrate the $50 \mathrm{ml}$ sample with $0.1 \mathrm{~N}$ sodium thiosulphate solution until the yellow colour has almost disappeared. Add about 1 $\mathrm{ml}$ of starch solution and continue titration until the blue indicator colour just disappears. Record the volume of sodium thiosulphate solution used.

To calculate the iodine number of the carbon was used the following equation:

$$
\mathrm{X} \%=\frac{\left(\mathrm{V}_{0}-\mathrm{V}_{1}\right) * 0.0127 * 100 * 50}{\mathrm{~m} * 10}
$$

Where:

$$
\begin{aligned}
& \mathrm{V}_{1} \text { - volume of sodium thiosulphate solution, } \mathrm{ml} \\
& \mathrm{m} \text { - mass of activated carbon, } \mathrm{g} \\
& 50 \text { - iodine solution of } 0.1 \mathrm{~N} \text { added into weighed sample, } \\
& \mathrm{ml} \\
& \mathrm{V}_{0} \text { - the volume of thiosulphate for blank test, } \mathrm{ml}
\end{aligned}
$$

0.0127 - the atomic mass of iodine in $1 \mathrm{ml} 0.1 \mathrm{~N}$ thiosulphate solution

\section{RESULTS AND DISCUSSION}

The results of ultimate, proximate and petrographic analysis of coal sample from Ereen deposit are shown in Table 1 and 2.

Table 1. Proximate and ultimate analysis of Ereen coal, \%

\begin{tabular}{lcccccccc}
\hline \multicolumn{4}{c}{ Proximate analysis } & \multicolumn{6}{c}{ Ultimate analysis, daf } \\
$\mathrm{W}^{\mathrm{a}}$ & $\mathrm{A}^{\mathrm{d}}$ & $\mathrm{V}^{\mathrm{daf}}$ & $\mathrm{S}_{\mathrm{t}}{ }^{d}$ & $\begin{array}{c}\mathrm{Q}^{\mathrm{daf}} \\
\mathrm{Kcal} / \mathrm{kg}\end{array}$ & $\mathrm{C}$ & $\mathrm{H}$ & $\mathrm{N}$ & $\mathrm{O}$ \\
\hline 1.8 & 16.6 & 45.5 & 1.25 & 7308 & 73.2 & 5.5 & 1.59 & 18.4 \\
\hline
\end{tabular}

Results of proximate and ultimate analysis indicate that the coal from Ereen deposit is a low rank D mark hard coal. For the characterization of coal of Ereen deposit have been used FTIR analysis (Figure 1).

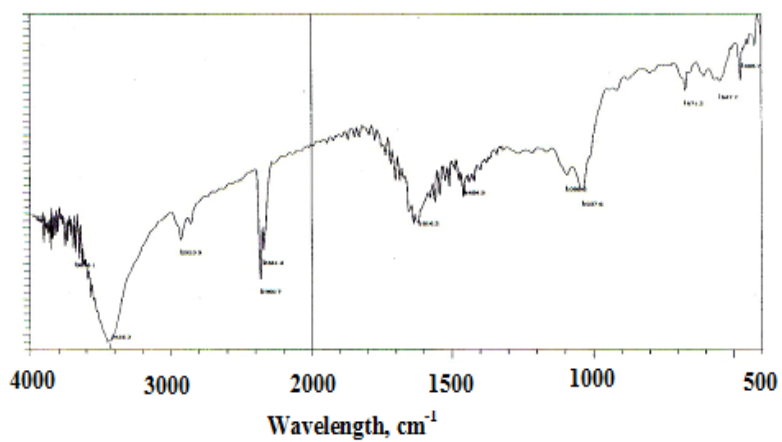

Fig. 1. The FT-IR spectra of coal from Ereen deposit

The FTIR spectra show that there are absorption frequency regions: $700-900 \mathrm{~cm}^{-1}$ for Car- $\mathrm{H}, 1000-1200$ $\mathrm{cm}^{-1}$ for $\mathrm{C}-\mathrm{O}-\mathrm{C}, 1300-1550 \mathrm{~cm}^{-1}$ for of $-\mathrm{CH},-\mathrm{CH}_{2}$ and $-\mathrm{CH}_{3}$ groups; $1550-1700 \mathrm{~cm}^{-1}$ for skeletal vibrations of aromatic rings, $>\mathrm{C}=\mathrm{O}$ bonds in ketones, aldehydes and quinines; $2800-2900 \mathrm{~cm}^{-1}$ for stretching vibrations of $-\mathrm{CH},-\mathrm{CH}_{2}$ and $-\mathrm{CH}_{3}$ groups in saturated aliphatic structures; and $3425 \mathrm{~cm}^{-1}$ for stretching associated vibrations of $-\mathrm{OH}$ groups in aromatic rings and $\mathrm{N}-\mathrm{H}$ stretching. Petrographic analysis have been carried out on a polished coal samples using the same microscope and software by point counting of 500 individual macerals. The white-black and colored petrographic photographs are presented in Figure 2 and the maceral group (vitrinite, inertinite and liptinite). The analysis of petrography of Ereen coal deposite suggested that the contents of vitrinite, liptinite, inertinite and minerals was $63 \%, 3 \%, 7 \%$ and $27 \%$ respectively. The vitrinites in grey coloured fragments with different sizes and stripes are shown in Figure 2A, the associated mineral binder is in yellow coloured background (see Figure $2 \mathrm{~B}$ ). The minerals in the polished coal sample are observed as brilliant pieces in the microscope, but they are absent in black-white (a) and coloured (b) images. The degree of vitrinite reflectance was measured and it equals (VR) to $0.59 \%$. The results of technical characteristics, elemental and maceral group composition degree of vitrinite reflectance show that Ereen coal corresponds to low rank D mark hard coal, which is suitable for thermal 


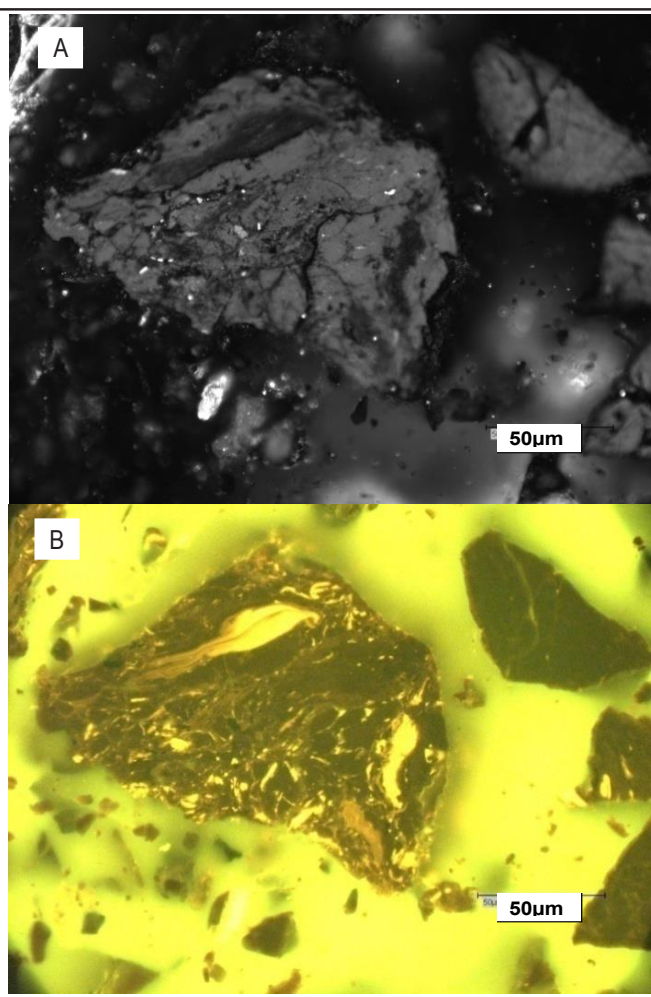

Fig. 2. The black-white $(A)$ and coloured $(B)$ petrographic images of coal sample

processing like pyrolysis and thermal dissolution.

The Ereen coal was pyrolized in a bigger scale retort at $550-700^{\circ} \mathrm{C}$ and the yield of pyrolysis products including char, tar, pyrolysis water and gases (Table 2) are determined.

Table 2. The results of pyrolysis experiments, $\%$

\begin{tabular}{cccc}
\hline T, ${ }^{\circ} \mathrm{C}$ & Char & $\begin{array}{c}\text { Tar + Pyrolysis } \\
\text { water }\end{array}$ & Gas and losses \\
\hline $550-700$ & 71.1 & 15 & 13.9 \\
\hline
\end{tabular}

As can seen from Table 3 that $71.1 \%$ of the coal is remained as a hard residue or char after pyrolysis. The yield of liquid and gas products is $28.9 \%$, which show that there was an intensive thermal decomposition of the coal organic mass with higher degree of conversion. Also the thermal dissolution experiments of Ereen coal in the medium of tetralin (hydrogen donor solvent) have been carried out in a laboratory scale autoclave at $350-450^{\circ} \mathrm{C}$ and the yields of thermal dissolution products including char, tar and gases (Table 3 ) were determined.

Table 3.The results of thermal dissolution, \%

\begin{tabular}{cccccc}
\hline $\begin{array}{c}\text { Donor } \\
\text { solvent }\end{array}$ & $\begin{array}{c}\text { Coal: } \\
\text { Solvent }\end{array}$ & T, ${ }^{\circ} \mathrm{C}$ & Char & Tar & $\begin{array}{c}\text { Gas and } \\
\text { losses }\end{array}$ \\
\hline \multirow{3}{*}{ Tetralin } & \multirow{2}{*}{$1: 1.8$} & 400 & 41.7 & 18.4 & 39.9 \\
& & 450 & 30.0 & 38.0 & 32.0 \\
\hline
\end{tabular}

Table 3 shows that the yield of char decreases and yields of thermal decomposition products (tar and gas) increases intensively with increasing of heating temperatures. The highest yield $(38 \%)$ of tar and gas gives at temperature of $450^{\circ} \mathrm{C}$. In this condition $30 \%$ of organic mass of Ereen coal remained as a hard residue. The yield of liquid and gas products is $70 \%$ (for the calculation of this yield have been taken the amount of used coal and tetralin).

The aim of next experiments was to determine the technical characteristics of obtained products from pyrolysis and thermal dissolution. The results of technical characteristics of initial coal and hard

Table 4. Characteristics of solid product of pyrolysis and thermal dissolution of Ereen coal, \%

\begin{tabular}{lcccc}
\hline Samples & $\mathbf{W}^{\mathbf{a}}$ & $\mathbf{A}^{\mathbf{d}}$ & $\mathbf{V}^{\mathbf{a}}$ & $\mathbf{V}^{\text {daf }}$ \\
\hline Initial coal sample & 1.8 & 16.63 & 37.25 & 45.52 \\
$\begin{array}{l}\text { Activated coal } \\
\text { sample }\end{array}$ & 2.3 & 25.44 & 7.82 & 10.73 \\
$\begin{array}{l}\text { Pyrolysis char } \\
\text { Char of thermal }\end{array}$ & 0.38 & 22.52 & 9.71 & 12.58 \\
dissolution at $450^{\circ} \mathrm{C}$ & 0.42 & 52.44 & 15.95 & 33.65 \\
\hline
\end{tabular}

residues after pyrolysis and thermal dissolution are given in Table 4.

Table 4 shows that the yield of volatile matter $(\mathrm{V}$, $\%$ ) of the char from thermal dissolution and pyrolysis char was decreased with 2.33-3.83 times than that of initial coal, which is an indication of intensive thermal decomposition of the coal organic mass.

One of the important applications of the hard residue after thermal processing is to produce activated carbon. For this reason the hard residue after pyrolysis was activated by preheated water steam at $800^{\circ} \mathrm{C}$ for $120 \mathrm{~min}$. and the adsorption capacity of iodine of the

Table 5. The adsorption capacity of activated hard residue after pyrolysis

\begin{tabular}{llccc}
\hline Samples & $\mathbf{T}^{\circ}{ }^{\circ} \mathbf{C}$ & $\begin{array}{c}\text { Piece, } \\
\mathbf{m m}\end{array}$ & $\begin{array}{c}\text { Time of } \\
\text { activation, } \\
\text { min }\end{array}$ & $\begin{array}{c}\text { lodine } \\
\text { adsorption, } \\
\%\end{array}$ \\
\hline $\begin{array}{l}\text { Initial coal } \\
\begin{array}{l}\text { Pyrolysis } \\
\text { char }\end{array}\end{array}$ & 0 & $1.5-0.63$ & 0 & 2.18 \\
$\begin{array}{l}\text { Activated } \\
\text { char }\end{array}$ & 800 & $1.5-0.63$ & 0 & 17.04 \\
\hline
\end{tabular}

obtained activated carbon samples were determined (Table 5).

Table 5 shows that the ability of iodine adsorption of activated carbon is increased 8.9 times by steam activation. It means that mainly micro and meso pores have been formed during the pyrolysis and activation of Ereen coal.

The SEM analysis of prepared activated carbons from pyrolysis and thermal dissolution is presented in Figure 3.

As it can seen that the SEM images are different for samples, e.g. the SEM image of initial coal has a compact solid piece, while the carbonized and activated carbon samples are hard material with high developed 


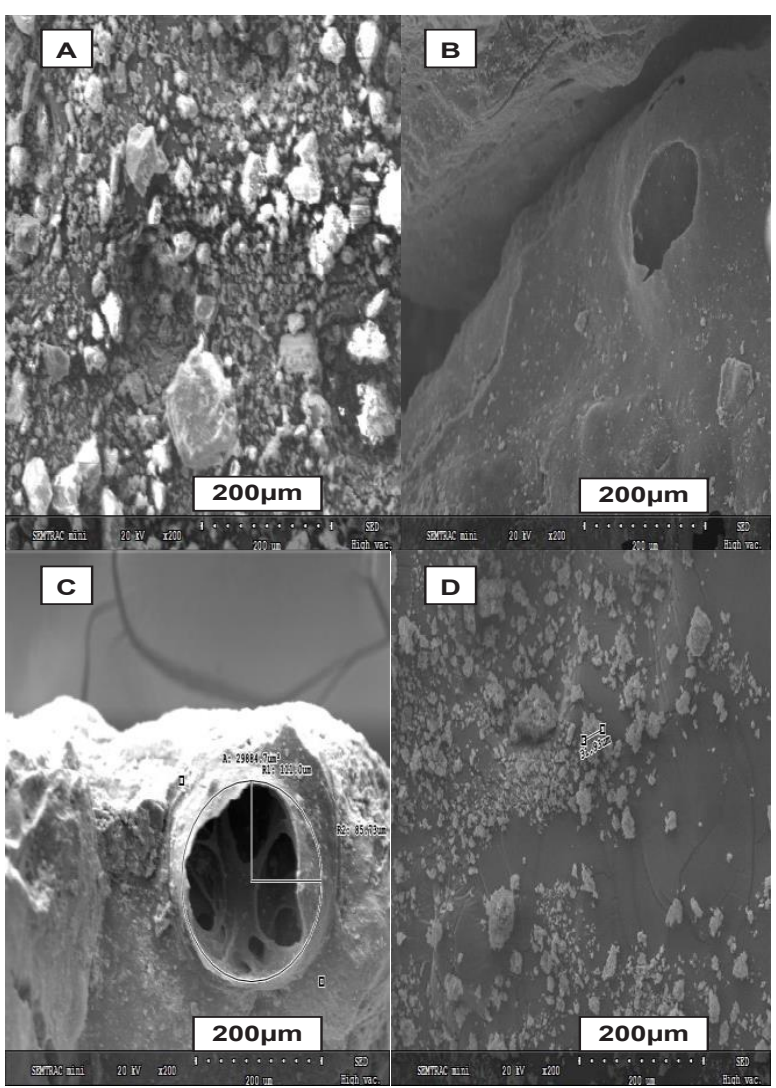

Fig. 3. SEM images of the initial coal (a), char (b), activated char from pyrolysis (c) and thermal dissolution (d)

porosity structure. The SEM image of hard residue after thermal dissolution in autoclave characterizes hard pieces with micro porous structure in comparison with the activated carbon sample.

\section{CONCLUSIONS}

1. On the basis of proximate, ultimate, petrographic and FTIR analysis, it can be concluded that the Ereen coal is a low rank $D$ mark hard coal, which is suitable for thermal processing including pyrolysis and thermal dissolution.

2. The results of pyrolysis experiment of Ereen coal show that $71.1 \%$ of coal organic mass remained as a hard residue by pyrolysis. The yield of liquid and gas products is $28.9 \%$ which shows that there was an intensive thermal decomposition of the coal organic mass with higher degree of conversion.

3. The results of thermal dissolution of Ereen coal in tetralin with constant weight ratio of coal and tetralin $(1: 1.8)$ at $450^{\circ} \mathrm{C}$ show that $38 \%$ of the coal organic mass converts to liquid product.

4. The ability of iodine adsorption of activated carbon is increased by 8.9 times with steam activation. It means that mainly micro and meso pores have been formed during the pyrolysis and activation.

5. The SEM image of initial coal sample has compact solid pieces, while the carbonized and activated carbon samples are hard material with high developed macro porosity structure. The SEM image of chars from thermal dissolution characterizes hard pieces with microporous structure in comparison with that of activated carbon sample.

\section{REFERENCES}

1. Purevsuren B., Davaajav Ya., Erdenechimeg R. (2010) Investigation on largest coal deposits in Mongolia. Toonotprint, Ulaanbaatar, 212

2. Purevsuren B. (2007) Coal is the main source of energy. In Abstracts of papers, Second Korean and Mongolian energy conference, Yonsei University, Seoul, 13.

3. Munkhjargal Sh. (1985) The benefication of the Tevshiingovi and Tavantolgoi coals. Ph.D thesis, UGG,CSW, Praha.

4. Dugarjav J. (1995) Coking properties of Tavantolgoi coal. Report of the Institute of Chemistry, MAS, 1722.

5. Purevsuren B., Davaajav Ya., Navchtsetseg N., et al. (2009) Thermal processing of Baganuur coal from Mongolia. J. Annual Scientific Reports of the ICCT, MAS, 10(36), 122-131.

6. Tsedevsuren Ts. (1981) Hydrogenation of Bayanteeg coal of Mongolia. J. Chemistry of Solid Fuels, RAS, 6, 17.

7. Avid B., Purevsuren B., Paterson N., et al. (2004) An exploratory investigation on the perfomence of Shivee-Ovoo coal and Khoot oil shale from Mongolia. J. Fuel, 83, 1105-1111.

8. Avid B., Purevsuren B., Born B., et al. (2002) Pyrolysis and TG analysis of the Shivee Ovoo coal Mongolia. J. Thermal Analysis and Calorimetry, 68, 877-885.

9. Ueda Sh. (1995) Preliminary survey on the Mongolian coal. J. Annual Summary of Coal Liquefaction, 19, 140-150.

10. Taylor G.H., Teichmüller M., Davis A., Diessel C.F., R. Littke., et al. (1998) Organic Petrology, Gebr. Borntraeger Stuttgart, 704. 